\title{
'Lo humano' y la experiencia mística desde el relato de Etty Hillesum
}

\author{
ROSANA E. NAVARRO \\ Pontificia Universidad Javeriana (Colombia) \\ rosana.navarro@javeriana.edu.co
}

\begin{abstract}
Resumen
En el ámbito de la situación presente de crisis de lo humano, así como de la efusión actual del fenómeno místico, esta reflexión se aproxima a la experiencia mística contemporánea a través de uno de sus testigos: Etty Hillesum. El acercamiento a la trama narrativa de su diario hizo posible que el decir del ser, el decir sobre lo humano en la experiencia mística se abriera paso a través de un ejercicio hermenéutico existencial con la mediación del relato. El asunto central consistió en buscar en la experiencia mística la raíz y expresiones de su fuerza humanizadora. En este sentido, a partir de una aproximación a 'lo humano' desde las categorías: interioridad, actitud teologal y alteridad, la reflexión abrió el paso a la consideración sobre la experiencia mística y su conexión con 'lo humano' que busca humanidad. Asunto éste que hizo posible plantear algunas perspectivas que contribuyan a explicitar el potencial humanizador de la Experiencia Mística hoy.
\end{abstract}

Palabras clave: Experiencia mística, condición humana, Etty Hillesum.

\section{'The Human Condition' and the Mystical Experience from Etty Hillesum's diaries}

\begin{abstract}
In the ambit of the present situation of the crisis of the 'buman', as well as of the current outpouring of the mystic phenomenon, this reflection approaches contemporary mystical experience by one of its witnesses: Etty Hillesum. The approach to the narrative of her diary made it possible to say of the "being", which is to say about the human in the mystical experience would open a way through a bermeneutic existential exercise with the mediation of the story. The main issue consisted of searching in the mystical experience, the root and expressions of its humanizing force. In this sense, from an approximation to the 'buman' from the categories: interiority, theological attitude and otherness, the reflection opened the way for consideration on the mystical experience and its connection with the 'buman' which seeks its humanity. This matter which made it possible to set out some perspectives that contribute to make explicit the humanizing potential of the Mystical Experience today.
\end{abstract}

Key words: mystical experience, human condition, Etty Hillesum.

Doctora en Teología. Profesora de la Facultad de Teología de la Pontificia Universidad Javeriana. Entre sus publicaciones: El lugar de la Espiritualidad en la acción docente del Teólogo (2010); De lo humano vulnerado a lo humano resignificado desde la experiencia espiritual de Etty Hillesum (2015). El presente artículo expone parte de los resultados de la investigación doctoral concluida en el 2015.

Recibido: 28/Marzo/2016 - Aceptado: 20/Mayo/2016 


\section{Introducción: Lo humano y la experiencia mística como propuesta de una reflexión teológica}

Desde que Malraux afirmó que "el problema capital del final de siglo será el problema religioso" (Martin Velasco, 2007a) y luego Rahner planteó que "el cristiano del futuro o será un místico, una persona que ha experimentado algo, o no será" (Rahner, 1980: 375) muchos estudiosos han buscado alternativas para dar viabilidad a este planteamiento de corte profético. Esta demanda se hace mayor en el momento actual, particularmente crítico por su complejidad, por la confluencia de un nuevo despertar religioso y un desplazamiento hacia la interioridad, en medio del inminente peligro de afirmar la deshumanización.

A la base de la actual situación subyace un asunto de humanidad. El ser humano, en medio del extraordinario desarrollo científico y tecnológico, no ha logrado desarrollar del mismo modo toda su capacidad espiritual y su compromiso ético. Esta investigación se enmarca en el ámbito de la situación presente de crisis de lo humano así como en la efusión actual del fenómeno místico y el reconocimiento de la experiencia como su centro, con el propósito de encontrar allí la raíz y las expresiones de su fuerza humanizadora. Esto ha sido posible desde la experiencia específica de los testigos; en este caso, la experiencia mística de Etty Hillesum, cuyo itinerario se movió del ámbito antropológico-existencial al religioso. Así, sobre la base de algunas intuiciones teológicas, de las sospechas acerca de la actualidad y pertinencia de la mística, y del deseo de concreción de la idea acerca del porvenir místico de la humanidad, la investigación se propuso indagar acerca del sentido y comprensiones de lo humano en la experiencia mística contemporánea encarnada en Etty Hillesum. Se planteó como pregunta central: ¿Qué sentido y comprensiones de lo humano devela la experiencia mística en el itinerario espiritual de Etty Hillesum, que permiten afirmar que la experiencia mística es una condición de posibilidad de humanidad para el creyente contemporáneo?

Para llevar a cabo esta propuesta, nos adentramos en un ejercicio hermenéutico mediatizado por el relato, lo cual implicó una aproximación a la trama narrativa en la que el decir del ser, el decir sobre lo humano en la experiencia mística se abre paso a través del análisis del diario

1 Carlos Floria, de la revista argentina Criterio, afirma que el escritor francés le confesó esto en una entrevista concedida en 1963. Por su parte, Juan Martín Velasco (2007: 14) afirma que en 1975, Malraux precisará "Se me ha hecho decir que el siglo XXI será religioso. Jamás he dicho tal cosa... Lo que digo es algo más incierto. No excluyo la posibilidad de un acontecimiento espiritual a escala planetaria”. 
de Etty Hillesum. Se buscó identificar la particularidad del fenómeno místico en la experiencia personal de esta mujer y el modo como emerge eso humano que humaniza, proceso de autocomprensión que se proyecta hacia una humanidad posible.

Este proceso implicó asumir la dialéctica comprensión-explicación como un movimiento de interacción con el texto siguiendo la pista desde lo que dice hasta aquello que es su referente, o aquello que señala, lo cual supone "avanzar desde una semántica de la superficie a una semántica de la profundidad" (Cubides, 1999: 270) o de un plano semántico a un plano reflexivo y a un plano existencial. El deseo de comprender y comprendernos, asunto que implica la subjetividad, pasa en este caso por una atención a lo dicho por el texto mismo (semántica), hasta los niveles de la reflexión y compromiso existencial.

En relación con las investigaciones y publicaciones existentes sobre el tema en cuestión, si bien, existe actualmente interés sobre la mística y su relación con el humanismo de parte de algunos estudiosos, y se han realizado algunas aproximaciones, no se ha llevado a cabo una aproximación a lo humano desde el testimonio de místicos contemporáneos, y en particular, desde Etty Hilleusm desde la perspectiva aquí propuesta. Aunque hay diversas aproximaciones a su itinerario espiritual, no ha habido hasta ahora ninguna motivada por la búsqueda de la especificidad de lo humano en su experiencia mística de modo que sea posible llegar a desplegar unas claves de humanización para el creyente de hoy, ávido de experiencia de infinito.

Al delimitar la investigación a la época contemporánea, es importante aclarar que no se trata de definir o analizar al ser humano desde la mística, sino del modo en que se hace posible la humanización desde la experiencia mística contemporánea. Una cosa es cómo ser místico hoy, y otra es como abrir las posibilidades de humanización desde la experiencia mística. Lo segundo es lo que nos interesa.

Por su parte, para la realización del estado del arte se tuvieron en cuenta los autores y obras a partir de la segunda mitad del siglo XX. Hay escritos sobre religión y humanismo (Moeller, 1967) sobre mística y humanismo (Gutiérrez Cuartango, 2008; Mommaus, 2003). Sobre este tema, es particularmente interesante el libro de Martin Velasco (2007b), que de modo directo aborda el asunto del potencial humanizador de la mística. Entre los aportes existentes en relación con la mística contemporánea y sus místicos, Francesc Torralba (2009) se refiere explícitamente a la necesidad del humanismo para enfrentar el siglo XXI y a la pertinencia de acceder a figuras como Edith Stein.

Dentro de la bibliografía existente acerca de Etty Hillesum, se pudieron identificar al menos cinco perspectivas diferentes desde las cuales se 
ha investigado y publicado: La filosofía, la psicología, la perspectiva de género, la mirada judía y del holocausto, y finalmente la teología cristiana. Una revisión de la literatura en relación con cada uno de estos tópicos, permitió identificar las tendencias, avances y las posibilidades que motivaron esta investigación.

Las veinte contribuciones realizadas al Congreso sobre Etty llevado a cabo en Gent (en el año 2008), junto con los artículos y libros que se han escrito, plantean desde distintas disciplinas e intereses, los avances y desafíos en los estudios sobre Etty Hillesum. Entre los autores que de modo más directo se han aproximado a lo humano y la mística en el itinerario espiritual de Etty, se encuentran Paul Lebeau (1999), González Faus (2008a). Estos autores están de acuerdo en reconocer el carácter místico de la experiencia espiritual de Etty, así como la similitud de su experiencia con algunos grandes místicos tanto del cristianismo como de otras religiones. Particularmente, la religiosa carmelita Cristina Dobner (2007), se aproxima a Etty con el propósito de estudiar el carácter místico de su experiencia espiritual.

Hay un acuerdo entre los autores de considerar que como fruto de esta experiencia espiritual, Etty Hillesum se hace consciente del dinamismo de la existencia humana y por tanto de la importancia de la presencia del otro. Es aquí donde lo humano comienza a abrirse camino. A partir de lo anterior, el propósito ha sido explicitar una comprensión de lo humano y de la experiencia mística, caracterizar la particularidad de lo humano desde la experiencia mística de Etty Hillesum para, finalmente, determinar el lugar y sentido de la relación entre la experiencia mística y lo humano en el mundo contemporáneo con algunas perspectivas que contribuyan a la resignificación de lo humano en la vida del creyente contemporáneo.

\section{El testimonio del sujeto como recurso irrenunciable}

Sobre la experiencia mística solo podemos conocer acercándonos a sus testigos y protagonistas y así, acceder a lo humano y a la humanidad mediante la particularidad de la experiencia del hombre o de la mujer denominados místicos.

En el escenario de la mística contemporánea, en medio de un significativo abanico de rostros, destaca por la particularidad de su experiencia, la figura de Etty Hillesum,una joven holandesa de origen judío que murió a los 29 años en el campo de concentración de Auschwitz, cuya historia personal e itinerario espiritual reflejados en su narrativa autobiográfica resultan suficientemente inquietantes y están siendo fuente actual de investigación desde diversas disciplinas. Según afirma Paul Lebeau (1999: 
10), refiriéndose a escritores como Abel Herzberg, el diario de Etty Hillesum puede ser considerado como una de las cumbres de la literatura holandesa. También, filósofos como Juan Martin Velasco (2011: 56) y García Baró, y teólogos como Paul Lebeau (1999) y González Faus (2008a) reconocen estar en presencia de una narración que muestra un proceso interior de estremecedora intensidad.

En el estilo de vida de Etty Hillesum y en su itinerario espiritual, es posible vislumbrar la situación de tantos creyentes en el mundo, quienes ante la ausencia de respuestas y sentido desde la religión o la institución, emprenden una nueva búsqueda que brinde alguna salida. El caso de Etty es un camino progresivo de encuentro con Dios, con la fe, animado también por sus variadas lecturas, entre ellas, las Confesiones de San Agustín, las obras del poeta Rilke, la Biblia, y también Dovstoyevsky. En su experiencia espiritual, logró encontrarse con el sentido de su existencia. El testimonio evidenciado en el diario no sólo es muy cercano al hombre y la mujer de hoy, sino particularmente pertinente a una teología que en su reflexión pretenda reconciliar la mística y 'lo humano'.

La aproximación hermenéutica narrativa a los escritos de Etty Hillesum permitió descubrir el decir sobre lo humano en su experiencia espiritual y así confirmar que "la experiencia de nuestro existir en el mundo debe conferir sentido y realidad a nuestro hablar teológico" (Schillebeeckx, 1973: 19) y, por tanto, "la teología se hace hermenéutica en la medida en que comprende que no hay afirmación sobre Dios que no implique una afirmación sobre el hombre" (Geffré, 1984: 39).

\section{Aproximación a lo humano y la experiencia mística}

Al plantear una comprensión sobre 'lo humano' y la experiencia mística se evidencia una relación de mutua implicación entre ambos. Como el ser humano no es la plenitud de 'lo humano', tiene que valerse de ese impulso de crecimiento y evolución hacia la plenitud de su existencia.

\subsection{Lo humano como lugar de la experiencia espiritual}

Lo humano es una cuestión no resuelta, difícil y compleja; por tal razón es preciso preguntarnos por aquello que implica existencialmente ser humano, conseguir la humanidad, humanizarnos, pues lo inhumano está fundido en lo humano, y así la búsqueda de humanización es proyecto de sentido de la existencia.

Inquirir por 'lo humano', no ha sido fácil; responder a esta cuestión está sujeto a muchas posibilidades y condiciones, entre ellas, su relación con la cultura que hace que cada época construya su propia aproxima- 
ción a lo humano. Lo interesante de esta pregunta radica en que su respuesta comienza a desentrañarse al transformar la forma de preguntar. No es lo mismo preguntarse ¿qué es el ser humano?, ¿quién es el ser humano? o sencillamente preguntarse ¿qué es lo humano? Y por tanto ¿qué implica -existencialmente- ser humano? es decir, conseguir la humanidad, humanizarse; un proceso siempre en evolución.

Hoy lo humano se nos presenta principalmente como posibilidad y como capacidad, como realidad que señala algo más allá y exige la búsqueda incansable. "Lo humanum es multidimensional, y ninguna de sus dimensiones puede por sí sola abrazar la totalidad de la vida humana" (Panikkar, 2000: 30).

Lo humano hace referencia a una existencia encarnada con todo lo que ello implica: comenzando por la fragilidad, vulnerabilidad biológica dadas las dificultades provocadas por la incapacidad natural para sobrevivir y la necesidad de asumir la existencia como esfuerzo y trabajo permanente. Así, en este descubrir lo humano, se evidencia un rasgo original, nuestra corporeidad está impregnada de la conciencia sobre ella: El cuerpo se da cuenta, es consciente.

En la tradición judeo-cristiana, la antropología hebrea construye una relación original entre las realidades de la carne y el espíritu, basár y ruaj que plantean un sentido de unidad de la existencia humana. De esta manera, "la sangre, los oídos, los huesos, cada órgano es una facultad de la unidad viviente que es el hombre. No hay, entonces, estrictamente hablando una 'corporalidad', sino más bien una 'carnalidad' de la existencia espiritual del hombre en su radical unidad viviente" (Dussel, 1969: 26). Como "identidad encarnada" (Lévinas, 1987: 104) el ser humano es imposibilidad de ocultarse al otro, implicando con ello, la vulnerabilidad, el dolor, la enfermedad, el cansancio. De modo que hablar de lo humano es reconocer también la vulnerabilidad y la posibilidad de ser vulnerado. Lo inhumano se presenta de muy diversas formas y se refiere a todo aquello que no permite que lo humano se desarrolle.

Como parte de lo humano que somos, el ser humano es sujeto de libertad, está llamado a elegir permanentemente entre su propia aparente seguridad y la búsqueda de su crecimiento integral.

Ante la imposibilidad de ocultarse al otro, lo humano implica también existencia en relación, coexistencia con los otros, en virtud justamente de su identidad encarnada en la cual el lenguaje emerge como modo de ser, de expresar, de realizar. Se trata del requerimiento fundamental de comunicación. Así, el rostro del otro en el proceso de convivir y coexistir plantea la apertura a la 'projimidad' de la alteridad con sus implicaciones y consecuencias. Implicaciones que afectan "mi" ser encarnado como humano y el ser encarnado del "otro". "La alteridad es, 
pues, relación, que es lenguaje: se le da al Yo por la palabra; es subjetividad: forman una sociedad en la responsabilidad del Yo para con el Otro; es justicia y verdad, libertad, etc.” (Quesada Talavera, 2011: 393).

Por lo anterior, lo humano es a la vez limitación y posibilidad; somos conscientes de vivir a través de la experiencia de lo ilimitado e infinito como condición que hace posible la comprensión de lo finito y limitado. "Nada tan característico del ser humano como esa interior desproporción que hace de él una 'síntesis activa de finitud e infinitud' (Kierkegaard, 2009: 57) "un ser finito que se supera infinitamente a sí mismo" (Martin Velasco, 2004: 10).

Hoy lo humano reclama recuperar la humanidad, rencontrarse, humanizarse mediante un humanismo que comprenda su historia y que haga memoria, que reencuentre los motivos para conjugar "la apertura al Misterio de lo sagrado y divino con la compasión solidaria y efectiva por el ser humano y todo lo existente" (Mardones, 2003: 445). Si lo inhumano de alguna forma está fundido en 'lo humano', se comprende que la búsqueda de la humanización es el proyecto en el que adquiere sentido la existencia. Conseguir ser enteramente humanos no está a nuestro alcance, por ello en el saberse humano está el comprenderse como un misterio $^{2}$, y descubrir la radical apertura a la trascendencia:

El hombre es misterio. Lo es en su esencia misma... porque en su fondo original es un 'para sí' puramente referido a la plenitud del Misterio de Dios. Cuando hemos terminado de decir de nosotros mismos todo lo que el espíritu puede abarcar, todavía no hemos dicho nada si en todos esos enunciados no hemos incluido nuestra referencia al Dios incomprensible... no podemos comprender al hombre de otra manera que captándolo en su orientación, en su movimiento hacia la bienaventurada oscuridad de Dios (Rahner, 2002: 42).

De esta forma, lo humano también es consciencia del Otro, es disposición que favorece un descentramiento del sujeto hacia el Misterio, es escucha atenta y en libertad, es encuentro interpersonal, es consciencia de que "Dios es la verdad más profunda del ser humano" (Gelabert, 1983: 18).

\subsubsection{Alteridad como modo de ser humano}

El domingo 15 de junio de 1941 Etty Hillesum escribía:

2 Es decir como realidad que supera todos los presupuestos y que a la vez los trasciende e ilumina.

VERITAS, No 35 (Septiembre 2016) 
He buscado mirar cara a cara el dolor de la humanidad, con honestidad y coraje, lo he enfrentado, lo he hecho parte de mí. Muchas preguntas han encontrado respuesta. El absurdo ha cedido su espacio a un poco de orden y coherencia, ahora puedo seguir adelante de nuevo. Ha sido otra breve pero violenta batalla de la cual he salido con un poco más de madurez. $\mathrm{He}$ escrito que me he confrontado con el 'dolor de la humanidad' (estas palabras me provocan todavía miedo) pero no es del todo preciso. Me siento como un pequeño campo de batalla en el cual se enfrentan los problemas, o al menos algunos problemas de nuestro tiempo. Lo único que se puede hacer es ofrecerse humildemente como un campo de batalla (Hillesum, 2013: 113).

En este fragmento Etty evidencia la conciencia sobre la humanidad, aún en medio de la ambivalencia y la duda en esa primera parte de su itinerario. Emerge en ella la novedosa posibilidad de un amor orientado a la humanidad entera con todas sus implicaciones. Así se fragua el camino hacia la realización del ser humano, en el establecimiento del otro, en la projimidad de la Alteridad, más allá de la otredad. Esta experiencia que supone la relación con el otro, cuyo rostro resulta interpelante, se constituye en el lugar donde la trascendencia se afirma. De modo que el soporte y raíz de la subjetividad es el acto de reconocer y acoger al otro, como camino y condición para la trascendencia, comprendida como una "relación con una realidad infinitamente distinta de la mía" (Lévinas, 1977: 65). El otro se me muestra, se me da, se me impone en la mediación del rostro que aparece, y se manifiesta expresándose.

La inquietud por el otro, que rompe con la indiferencia y suprime la distancia es en últimas el origen de la proximidad, que hace posible entrar en contacto con eso que se resiste a ser tematizado pero que en virtud de lo cual permite acceder a su real intimidad. En la proximidad, la alteridad se hace prójimo, emerge la sensibilidad, la exposición al otro, la vulnerabilidad: el dolor, el mal, la enfermedad. De esta manera, en la experiencia de la vulnerabilidad se nos conduce irreductiblemente al otro, a la donación hasta dar la vida y llenarla de sentido al tiempo que se vacía de sí misma.

Pero, alteridad, yo-otro, no están plenamente reconocidos o significados si omitimos que dicha alteridad implica el nosotros, el ser con, la comunidad, que en todo caso para los estudiosos de la filosofía política (Espósito, 2012) ha resultado un asunto bien complejo y difícil de desentrañar por cuanto, bajo el pretexto de la comunidad, aparecen las justificaciones más elaboradas de la destrucción de lo humano, la humanidad.

Así, toda reflexión sobre la alteridad no puede desconocer un nosotros como parte y consecuencia de su reflexión que en cualquier caso es 
un asunto complicado en tanto señala la fragilidad de las relaciones humanas. La comunidad, lugar de encuentro de lo distinto, aquello que es impulso que atrae a la vez es riesgo de una alianza que destruye. De modo que la alteridad es invitación y llamada y, también tensión y ruptura que desgarra.

Quizás, este nosotros que desgarra pueda tener una salida justamente en su propia recomprensión, un nosotros que se hace comunicación de las existencias, encuentro, amistad que se produce al ritmo propio de la progresiva madurez humana, que pasa por el amor, el odio, el placer, el dolor, el compartir sentimientos, pensamientos y propósitos comunes. Esta comunicación de las existencias es fruto de aquellas influencias de la infancia que disponen o indisponen para abrirse a lo otro, a la solidaridad personal que reconoce desde la convicción existencial profunda el deber sustentado en el amor para con el otro.

Este proceso de comunicación de las existencias supone como presupuesto y condición para que sea posible, la conquista personal de la libertad, algo que se va evidenciando en el itinerario personal de Etty Hillesum hasta lograr confesiones como ésta:

De noche, mientras estaba allí recostada en mi litera rodeada de mujeres y niñas que roncaban suavemente, soñaban en voz alta, o lloraban silenciosamente, o daban vueltas y vueltas. Mujeres y niñas que decían a menudo durante el día: -'no queremos pensar', 'no queremos sentir, de otra manera nos volveremos locas'-, a veces me envolvía una infinita ternura, estaba despierta y dejaba que pasaran delante los acontecimientos, demasiadas impresiones en un día muy largo, y pensaba: -'Ahora permíteme ser el corazón pensante de esta barraca' (Hillesum, 2013: 787-788).

Etty Hillesum ha descubierto la imposibilidad de permanecer indiferente ante la identidad encarnada y vulnerable del prójimo. Su posibilidad de ser, ha nacido del estar atenta y responder a la demanda del rostro del otro, que ha implicado un vaciarse de sí. De este modo, lo humano deviene en humanidad al suprimir la distancia y superar la indiferencia que deja expuesta la vulnerabilidad en la proximidad de la alteridad, y que permite comprender el paso de la pregunta, de la queja y de la súplica a la disposición irrefrenable de volverse "bálsamo derramado sobre tantas heridas" (Hillesum, 2013: 797).

En su búsqueda en medio del momento de confusión, atasco espiritual y emocional que vivía, se llena de preguntas y reflexiones al comienzo de su diario a propósito de todo lo que acontece dentro de ella. Dichas preguntas le conducen progresivamente a reconocerse a sí misma en 
su relación con Julius Spier ${ }^{3}$, en su relación con $\mathrm{Han}^{4}$, y a plantearse nuevas preguntas y reflexiones que fueron dando fuerza a su propio constituirse como ser humano.

¿Soy presuntuosa al decir que tengo mucho amor para darlo a una sola persona? La idea según la cual se debe amar durante toda la vida solamente a una persona me parece infantil. Hay algo empobrecedor en ello. ¿No aprenderá la gente que el amor provee mucha más felicidad y retribución que el sexo? (Hillesum, 2013: 793).

Entonces, "en la verdadera caridad, el principal parece querer que el otro sea amado como lo es él mismo: en el amor mutuo que arde al extremo nada más raro, nada más notable que tu voluntad de que 'otro' sea amado tanto por aquel a quien amas y por el cual eres amado" (Marion, 2006: 118). Así, Etty Hillesum se descubre y se reconoce como un ser humano capaz de conmoverse con el dolor del otro en virtud de la progresiva conciencia de saberse habitada y de saberse amada en la que fue revelándose poco a poco el amor de Dios en ella. En su experiencia, el amor no solo se intercambia, sino que se comunica: se convierte en comunión o confirmación del amor recíproco que se ensancha y se abre al tercero que también es amado. Para Ricardo de San Víctor este paso al tercero que confirma el amor recíproco se llama communicatioamoris, comunión que supera la reciprocidad y se abre a una tercera persona condilectus (coamado), como condición de perfección del amor inicial de dos.

En su relación con Julius, Etty Hillesum fue comprendiendo la lógica del amor, este hallazgo le fue mostrando la prioridad del otro, en el cual se fue revelando el '¡Tú, tú has amado primero!'. Es decir, en la experiencia de sentirse amada, descubre a su vez, el amor primero, el amor de Dios. Etty logra descubrir y experienciar este gozo que la refiere a Dios, y por Él, vive la experiencia y la necesidad de hacerse prójimo: "Después de todo lo que importa no es que yo sea comprendida sino que sea capaz de ayudar a los otros en el modo que creo correcto. Señor, no me concedas el deseo de ser comprendida. No importa si parezco ridícula, es un riesgo que estoy dispuesta a tomar" (Hillesum, 2013: 326).

De esta manera Etty Hillesum llega a afirmar en su diario: "Amo tanto al prójimo, porque amo en cada uno un trocito de Ti, Dios. Te busco en todos los seres humanos, y a menudo encuentro en ellos algo

3 Julius Spier tuvo un papel central en la vida de Etty Hillesum como su guía, orientador, acompañante y terapeuta.

4 Han Wegerif, dueño de la residencia donde Etty vivió sus últimos años antes de ser recluida en el campo de concentración. Etty y Han fueron amantes durante este período. 
de Ti. Intento desenterrarte de los corazones de los demás" (Hillesum, 2013: 750).

\subsubsection{La actitud teologal que dinamiza lo humano}

El problema de Dios hace parte de la realidad que nos identifica como seres humanos. Se refiere a la dimensión que nos constituye mucho antes de la pretensión de cualquier decir acerca de Dios. Por eso es teologal, y por eso exige y demanda la búsqueda del fundamento último de la realidad como algo que resulta imposible de rehuir. Dios es sin duda un problema que el ser humano debe afrontar sensatamente, puesto que su propia estructura humana así lo exige.

Existe pues, una realidad que nos enfrenta a la necesidad irrenunciable de un fundamento último, un referente radical de la existencia. Puesto que "el poder de lo real en las cosas no es sino el acontecimiento del fundamento en ellas" (Zubiri, 1997: 55), el ser humano se ve enfrentado a este poder en cuanto su vida solo se puede desarrollar frente a las cosas que le exigen además optar, ejercer su libertad. Hablamos de la dimensión teologal según Zubiri (1997: 56), un momento constitutivo y estructural de lo humano en su relación con la ultimidad de lo real. Esto quiere decir que Dios como expresión de la ultimidad de lo real, emerge como problema para el ser humano, en el autodescubrimiento de la propia realidad humana como problema. De modo que "la capacidad de trascendencia del hombre le hace posible descubrir aquello de lo que carece, que sabe que pertenece a su entraña y, sin embargo, no lo puede descubrir y, cuando descubre dónde se sitúa, no lo puede conquistar" (González de Cardedal, 1997: 26).

En ocasiones, dirá Martín Velasco, esta "dimensión teologal de la persona desaparece de determinados proyectos de vida por falta en ellos de la hondura, la seriedad, la autenticidad indispensables para que aflore a la conciencia" (2007: 170) o, lo que es lo mismo, por llevar una vida exclusivamente desde y en la superficie, por creer que se cree, por creer lo heredado, o por ya no desear creer lo que siempre se ha creído, o vivir bajo el efecto del estar programados.

Este dinamismo se hace actitud teologal, se hace experiencia en cuanto emerge a la consciencia ese secreto deseo de Dios en el alma, es descubrimiento de la realidad-fundamento del poder de lo real, hallazgo de Dios por la persona y en la persona, en el proceso de realización en su itinerario vital. En el emerger de lo bumano se evidencia una vivencia compartida en toda la historia: "la experiencia de que somos conscientes de la trascendencia, de lo más, lo otro, lo infinito, lo desconocido, el misterio" (Panikkar, 1999: 10). Es "reconocer e invocar la Presencia Originante 
como un Tú que con su provocación convierte nuestra vida en don y tarea" (Martin Velasco, 2007: 83).

Etty nos muestra un itinerario de búsqueda de sentido, y de progresiva confianza. Varias veces se refiere explícitamente a esta búsqueda personal: "Uno se pregunta por sentido de la vida, si aún tiene sentido, pero para responder esa pregunta es preciso tratar exclusivamente con uno mismo y con Dios. Quizás cada vida tiene su propio sentido. Se requiere una vida entera para lograr encontrarlo" (Hillesum, 2013: 111). A esto se añade la intranquilidad que le provoca:

Me siento agitada debido a una extraña y diabólica intranquilidad que podría ser productiva si supiera hacer algo con ella: es una intranquilidad 'creativa', no es física, pues ni siquiera una docena de noches de amor apasionadas podría calmarla. Es casi una intranquilidad 'sagrada'. Dios mío tómame de la mano y hazme tu instrumento, haz que pueda escribir (Hillesum, 2013: 119).

Así, la intuición sobre Dios y el significado personal en su vida, comienza para ella como una intranquilidad sagrada.

En su proceso personal va descubriendo que su apoyo no lo constituye ninguna razón o posibilidad humana. Su fe se irá asentando en Dios en medio de la desesperanza. Así mismo, la fe le permite experienciar su condición humana finita pero habitada por el Misterio que mueve, desinstala y dinamiza. A pesar de que varias veces se reprocha la falta de confianza en sí misma, llega a afirmar:

En algunos momentos es como si la vida se me rebelara transparente y también el corazón humano y puedo ver y entender más, y dentro de mí estoy en paz. Hay en mí una confianza en Dios que ha crecido muy rápido, que al comienzo me asustó por su crecimiento veloz, pero ahora me resulta inseparable, es parte de mí (Hillesum, 2013: 702).

La fe, en la experiencia personal de Etty, es además una fe que humaniza. Creer en la humanidad a toda prueba, no se reduce como afirma Schillebeeckx a "ser un acto de voluntad positivista, pues sería tanto como querer salirse del pantano tirando uno mismo de sus propios pelos" (1994: 153). Se trata de una profunda experiencia de la Realidad, de la Alteridad Infinita, de modo que se hace posible comprenderla y aun vivirla como algo más que un estrecho callejón sin salida. Etty Hillesum ha logrado dar profundo sentido a su acto de donación. Su búsqueda personal le condujo a la experiencia de una verdad radical y disponer una acti- 
tud personal de profunda confianza en Dios que le condujo a cultivar la interioridad.

\subsubsection{Interioridad como profundidad y búsqueda}

Vivir la actitud teologal, la fidelidad, implica una apertura a la dimensión de profundidad de la existencia una aproximación y experiencia de la interioridad.

La interioridad es una dimensión antropológica fundamental, desde la cual emerge la conciencia, el sentimiento, la escucha atenta que mueve la sentencia clásica: "conócete a ti mismo" y que se orienta a la sabiduría nutrida desde el silencio. La interioridad es todo un mundo que integra y desborda al ser humano cuando es descubierto y reconocido. Por ello, es una conquista que exige tiempo y esfuerzo, y que puede hacerse por diversos caminos: la literatura, el arte, el contacto con la naturaleza, o desde las tradiciones religiosas. En todo caso, la interioridad está íntimamente relacionada con la espiritualidad. Esta última no subsiste sin aquella, pues es en lo que consiste la espiritualidad, el cultivo de la vida interior desde la cual se afirma y significa el sí mismo, los otros, el Otro.

Es muy clara para Etty Hillesum la fuerza que proviene del mundo interior: "No creo que podamos mejorar nada en el mundo exterior, sin haber primero hecho nuestra parte dentro de nosotros. Es la única lección de esta guerra: debemos buscar en nosotros mismos, no en otro lugar" (Hillesum, 2013: 366).

Etty Hillesum libra una batalla en su interior de la cual es muy consciente desde el comienzo de su diario: "A veces soy como un sangriento campo de batalla y esto lo pago luego con mucho agotamiento y un fuerte dolor de cabeza" (Hillesum, 2013: 113). Y también cuando afirma: "Sin embargo, hasta que la disciplina interior no esté en su lugar, la disciplina exterior será muy importante para mí” (Hillesum, 2013: 207).

Hay en ella al comienzo de su narración una sensación de confusión interior: "Así es que ahí estaba yo con mi constipación espiritual" (Hillesum, 2013: 33). Desde las primeras notas de su diario, comprende la importancia de cultivar su vida interior, su interioridad: "Pienso que lo haré: 'miraré dentro de mí' por una media hora cada mañana, antes de comenzar a trabajar: escucharé mi voz interior. Sickversenken, 'profundizar en uno mismo"' (Hillesum, 2013: 103).

En sus notas de fin de año de 1941, Etty, convencida de una fuerza interior que la sostiene, afirma "Y en ocasiones debo arrodillarme delante de mi cama, incluso en una fría noche de invierno, para escuchar 
dentro de mí, para no dejarme llevar por aquello que viene de fuera, sino por aquello que brota dentro de mí" (Hillesum, 2013: 320).

De modo que no se puede desconocer que la interioridad es algo que forma parte de lo que somos, que tiene que ver con sentimientos, pensamientos, razonamientos, encuentro con lo que realmente cada uno es, zona donde se gestan las motivaciones de la existencia, escenario de aproximación a la respuesta de la pregunta de la vida: ¿quién soy yo? ¿Qué sentido tiene mi vida? En este punto es importante señalar que la salud física y psicológica está fuertemente vinculada con el grado de autoconocimiento y auto-realización en relación con lo más profundo del ser de cada persona.

La interioridad, siendo el lugar de la propia historia, de la intimidad y el secreto, penetra aún más hasta hacer conciencia del propio ser en el Ser ${ }^{5}$, escenario de la verdad de la vida, de la radical concienciación de la vulnerabilidad y dependencia ontológica. A la vez, la interioridad es un moverse, un peregrinaje a la realidad, como Abraham, implicará un removerse, desarraigarse de la propia tierra para poder comprender que Dios constituye la interioridad del ser humano, “...tú estabas dentro de mí, más interior que lo más íntimo mío y más elevado que lo más sumo mío" (San Agustín, 2006: 49).

La interioridad no puede comprenderse separada de la alteridad, de la referencia al otro. Es el otro el que me permite ser yo, reconocerme en mi profundidad. El cultivo de la interioridad se ejerce en la mediación de la exterioridad. Así cobra sentido la expresión de Zubiri: inteligencia sentiente y el proceso inverso, sentir inteligentemente. De modo que, cuando la propia interioridad se desborda a sí misma en la experiencia de lo profundo, del Misterio, que le transforma y acompaña, se produce la experiencia de la Alteridad Infinita.

Por lo anterior, lo humano es vulnerabilidad, fragilidad, riesgo, y en ello también posibilidad, apertura, conciencia de eso otro de si hasta llegar a la escucha de ese secreto deseo de Dios en el alma, reconocimiento existencial del Otro, actitud teologal, confianza plena. También lo humano movido por esa confianza se abre a la sabiduría nutrida desde el silencio, deseo de recuperación de la esperanza que nace de lo profundo, del adentro. Es la interioridad, encuentro que envuelve y comunica, que invita a salir de sí, experiencia que remueve al ser humano de su ego, y le descubre la abertura existencial que le lanza hacia su Soporte Último, viven-

5 La carmelita Cristina Kaufmann afirma exactamente que la interioridad no es el lugar a donde uno se retira, sino más bien un caer en la cuenta, una toma de consciencia de estar dentro de Alguien, es de carácter dinámico, como una permanente fuerza centrípeta que lanza al Absoluto (Kaufmann, 2004: 53-68). 
cia profunda y aceptación gozosa del Fundamento que nos sostiene y transforma la existencia, orientándola hacia los otros, que en su vulnerabilidad se nos revelan prójimo, alteridad, gracia primordial, en cuanto el ser humano es con el otro, con los otros, en el Otro.

En esta perspectiva de lo humano y su comprensión en clave espiritual nos aproximamos a la mística y al fondo que la sustenta, la experiencia, cuya riqueza extraordinaria de significaciones etimológicas, filosóficas y teológicas no hace más que afirmar desde diversos modos y caminos el requerimiento fundamental de todo ser humano para afirmarse existencialmente como tal: salir de sí como apertura, encuentro y relación con el ser, correlación de intuición y pensamiento hacia una progresiva autoconciencia, y construcción plena en el encuentro, en el Tú, experiencia de Dios hacia el nosotros.

\subsection{La experiencia mística, un modo de vivir lo humano}

Si la mística incumbe a lo humano, "pertenece al mismo ser humano" (Panikkar, 2005: 21) entonces cualquier ser humano es potencialmente capaz de realizar esta dimensión. La dimensión mística está integrada a las demás dimensiones de la vida humana para conquistar lo humano.

La mística o dimensión humana del deseo como la llama Martin Velasco (2007b), provoca expresiones como estas:

¿Qué significa este instinto irresistible que nos lleva hacia la Unidad cada vez que nuestra pasión se exalta en una dirección cualquiera? Sentido del Universo, sentido del Todo: ante la naturaleza, ante la belleza, en la música... la nostalgia se apodera de nosotros, expectación y sentimiento de una gran Presencia [...] Resonancia en el Todo: he aquí la nota esencial de la poesía pura y de la pura Religión (De Chardin, 2009: 117).

Esta 'nostalgia de infinito' que nos constituye, es esperanza de reencuentro con la hondura y misterio de la propia humanidad, de modo que "si logramos bajar de veras, y no superficialmente a lo más hondo de nuestro yo y nuestra circunstancia, nos encontramos con lo universalmente humano" (González Faus, 2008b: 59). La dimensión mística es expresión de lo que Von Balthasar (1985: 16) denominó el misterio que todo ser humano lleva en su corazón y que es mayor que él mismo.

No es posible hablar de experiencia mística sin esa actitud previa de quien reconoce la dimensión teologal de su existencia, por ello, la primera y principal actitud fundamental humana de cara a la experiencia mística consiste en una radical pasividad, pues no hay esfuerzo humano por 
grande y profundo que éste sea, que por sí solo consiga aproximarse al Mysterium tremendum et fascinans, puesto que "la verdad es la que nos busca" (Panikkar, 2005: 46) y tan solo hemos de ponernos en su camino.

Martin Velasco (2007b: 32) propone unos presupuestos existenciales de la experiencia Mística cuyo punto de partida es la superación del apego que conduce al desasimiento. Renuncia que provoca la necesaria soledad que invita al cultivo de la interioridad y se goza en el silencio como escenario de la Palabra de Dios en el interior. Este proceso lleva a un segunda fase que el autor denomina "intervención depurativa" de parte de Dios. Supone una preparación que se da en medio de la prueba, del sufrimiento, algunas contrariedades, incluso la sensación de lejanía de Dios. El propósito de esta fase preparatoria de la experiencia mística es conseguir afianzar y consolidar el deseo profundo de Dios a partir de la vivenciación de su ausencia. Martin Velasco (2007b: 34) habla de "adelgazar nuestras facultades para que dejen transparentar al Dios que de ellas surgen". Paradójicamente esto requiere de un esfuerzo, aunque en este caso es un esfuerzo de despojo y liberador. Así, la vida se transforma para hacerse lugar del acontecer de Dios.

Desde esta comprensión es posible comprender la experiencia mística como esa forma específica de experiencia de fe, de experiencia de Dios, una forma de vivir la propia existencia en profundidad y en apertura a la Realidad: a los otros, al Otro. Es profundidad de sentidos, conciencia plena y posibilidad de aprendizaje permanente, estar presente plenamente en cada instante de la propia vida que invita y provoca la transformación, la comunicación, la realización humana desde el encuentro, desde el silencio que habla. Experienciar supone un conocer desde dentro, desde la propia relación con las cosas, no es una deducción intelectual, es vital, se padece, es conciencia vital que atrapa a la persona, la motiva y la anima a algo.

La experiencia mística pone en evidencia que la realidad es más de lo que es, que "el hombre supera infinitamente al hombre" (Martín Velasco, 2004: 10) que el ser humano es portador del Misterio, que es misterio en el Misterio (Galván, 2006: 163-167).

En este contexto de comprensión se descubre al místico como aquel sujeto que decide poner a funcionar esa dimensión y potencial de eternidad en el que se conjugan la consciencia de trascendencia, la interioridad y la alteridad. En un místico se conjugan la disposición y la sensibilidad para percibir la realidad en un horizonte más amplio. La interioridad del místico se constituye en la herramienta para construir, redescubrir y recrear el mundo. 


\section{Desvelamiento de lo humano desde la experiencia mística de Etty Hillesum ${ }^{6}$}

Etty Hillesum vivió una corta vida pero muy intensa hasta el momento de su muerte en el campo de concentración de Auschwitz. ¿Por qué su vida como la de tantos otros en similar situación, no aparece como inútil? ¿Qué es lo que hace de su diario un punto de encuentro y referente para muchos hombres y mujeres hoy? ¿Es la experiencia espiritual una salida ante la crisis de lo humano? ¿Cómo es posible? ¿Cómo desde la vida humana vulnerada es capaz de emerger una fuerza mayor que impide que todo quede en el vacío y ausencia de sentido? Incluso para llegar a afirmar:

La enorme fuerza consiste en considerar la vida aun cuando uno muera de forma deplorable, plena de sentido y hermosa, viendo todo lo que uno ha realizado en su interior y por lo que mereció la pena vivir. No puedo explicar esto mejor (Hillesum, 2007: 126).

Hablamos de una dimensión honda y fundamental del espíritu humano en donde el sufrimiento se transforma y significa a través de una acción terapéutica perfecta: la acción Divina que se pronuncia en la fragilidad humana. Esta dimensión honda y casi escondida del espíritu humano es capaz de emerger a la consciencia e irradiar sentido a todo el ser humano a pesar de su fragilidad, y gracias a su fragilidad.

En medio de una compleja personalidad, el proceso de relación con Dios de esta mujer se pudo identificar en 6 etapas sucesivas ${ }^{7}$ cuyo punto de partida fue su propia batalla interior que ella llegó a diagnosticar como su "constipación espiritual". Incluso algunos estudiosos hablan de su "bulimia existencial". El apoyo de Spier, su psicoanalista, fue fundamental para ayudarle a intuir en medio de su sensación de caos y división, esa añoranza incontenible, la nostalgia de "lo Otro de sî".

En la clave de su experiencia mística, el Dios incomprensible y silencioso, al que se refiere Rahner (2002), que pareciera brindar argumentos que justificaban el odio hacia los alemanes, ese Dios que permanece

6 En el texto completo de mi tesis doctoral titulada: De las razones humanas de la mistica a las raices misticas de lo bumano desde la experiencia espiritual de Etty Hillesum, se encuentra ampliamente desarrollado el tema de la experiencia mística de esta mujer judía.

7 1. De la batalla interior a la intuición de estar habitada; 2. Surge y se afianza la actitud teologal; 3. Oración de gratitud, diálogo y surgimiento del otro; 4. Tú vulnerable; 5. En el corazón de la humanidad; 6. La vida florece en la devastación, lo humano se nutre desde el interior.

VERITAS, No 35 (Septiembre 2016) 
oculto en lo más recóndito de la intimidad interior, al que es muy difícil acceder, es justamente el Dios de quien escribe Etty, por quien se conmueve y agita su interior y su vida entera.

Un Dios a quien se dirige conmovida, con absoluta confianza y sinceridad, de tú a tú. A fin de cuentas, para Etty el diálogo es el modo más genuino de llevar una relación. Su vida se va haciendo espacio de Dios, amistad e intimidad profunda.

De modo que la progresiva aparición de la certeza de la Presencia en ella -Presencia como el Tú cuya provocación convierte nuestra vida en don y tarea-, fue el detonante del nacimiento de la conciencia acerca de la necesidad inminente de convertirse en ayuda de Dios en medio de la humanidad, demostrando además la estrecha relación entre mística y compromiso, mística y alteridad. A través de su experiencia, Etty insinúa la vulnerabilidad ${ }^{8}$ de Dios, en quien afirma su fe: "Creo en Dios aunque dentro de poco los piojos me habrán devorado en Polonia" (Hillesum 2013: 672).

En medio de la particular y difícil situación, Etty se hizo memoria de sentido en medio del campo de concentración, dio un salto sobre los conceptos en los que inicialmente se sintió atrapada, su certeza interior la condujo al corazón de la humanidad:

Dios, lo siento en mí, este anhelo que sobrepasa las fronteras, que sabe descubrir un fondo común en todas las criaturas, incluso en las luchas que las enfrentan en toda la tierra. Y quisiera hablar de este fondo común, con dulce voz, persuasiva e ininterrumpidamente (Hillesum, 2013: 772).

La vida para Etty comenzó a florecer en medio de la devastación nutriéndose y afianzándose desde el interior. Es el emerger de 'lo humano' revelando su estrecha e íntima relación con la fuerza del cultivo de la interioridad que le provocó una toma de conciencia de la propia historia en diálogo con la historia de la humanidad. Consciencia de lo otro de sí que concentra, descentra y sobre-centra la existencia. Es el descubrimiento de Dios como la verdad profunda de la propia realidad.

Su experiencia espiritual auténtica la condujo irremediablemente al otro, su propia existencia personal se hizo escenario de encuentro interior y profundo, de hallazgo y liberación, de estremecimiento e ilumina-

8 Vulnerabilidad de Dios, a la cual es posible aproximarnos desde una 'teología de la vulnerabilidad divina', del 'pathos divino'. Sin pretender adentrarnos en la discusión sobre el sufrimiento de Dios, sí es posible afirmar que desde la mirada de Etty, Dios es 'tocado' por el sufrimiento humano, si bien el 'pathos' de Dios no se refiere a su esencia, sino al modo como Él se relaciona con el ser humano (De Almeida, 2014: 174176). 
ción cuyo sentido únicamente se expresa y se proyecta en el encuentro con los otros, con su voz, su rostro, su necesidad, su desamparo, su ser vulnerado, que despierta un acto de donación en aras de lo bumanum.

La unión mística en Etty Hillesum se tradujo en ayudar a Dios, ser Sus manos. Y así como la unión del cristiano con Cristo encuentra su manifestación más elevada en los sacramentos, en particular la Eucaristía. De modo muy similar, Etty siente la necesidad de expresar con profundo sentido sacramental el fruto de toda auténtica Eucaristía:

Cuando sufro por los seres humanos indefensos, ¿no sufro tal vez por el lado indefenso de mí misma? He partido mi cuerpo como si fuera pan y lo he compartido entre los hombres. ¿Y por qué no? Si estaban hambrientos desde hace tiempo (Hillesum, 2013: 797).

La aproximación y comprensión del texto, su Diario y algunas cartas fue haciendo accesible y veladamente explicita la particularidad de su experiencia mística: Desde su itinerario espiritual la experiencia mística se hace posible desde la experiencia del otro. Sólo desde la pregunta por el otro, desde la mirada más allá de sí, se da lugar a la experiencia del Misterio que es amor. Si bien, Etty no tuvo una experiencia eclesial, sí tuvo una experiencia que le ha remitido a los otros y al Otro.

La particularidad de su Experiencia mística ha consistido en el modo en que lo humano se afirma como tal, el modo como lo humano se humaniza, lo humano que se hace visible y posible como escenario de encarnación y como transparencia de lo interior en lo exterior. Es decir, Etty se encontró con lo genuinamente humano desde su experiencia mística para recuperar e interiorizar el sentido de ser imagen y semejanza de Dios. Imagen y semejanza en la que el ser humano ha sido creado, sentirse uno con Dios en virtud del don del ser (imagen) y en el estar orientados a Él desde el influjo del Espíritu (semejanza).

Desde la experiencia de Etty Hillesum, lo humano se hace tal al aprender a vivir la imagen y semejanza y esto es posible desde la experiencia mística, como experiencia de la lucidez originaria, como experiencia de la unidad en la que cobra sentido la apuesta por la humanidad, "humana unidad", conciencia gozosa de la única Fuente que nos hace ser.

\section{La esperanza de 'lo humano' como intuición y demanda de la experiencia mística}

La estrecha relación entre la experiencia mística y lo humano en el caso particular de Etty Hillesum, conduce a pensar que la experiencia 
espiritual en la dinámica del mundo actual puede hacer posible el rompimiento de algunas de las estructuras que niegan u ocultan humanidad.

En la misma perspectiva de los tres rasgos descritos acerca de lo humano: interioridad, actitud teologal y alteridad, ha sido posible evidenciar tres situaciones que dificultan o impiden hoy el desarrollo de lo humano.

-El eclipse de la alteridad, es una forma de negación de lo humano mediante el desconocimiento o rechazo de la vulnerabilidad, vulnerabilidad vulnerada que desmorona al ser humano condenándolo al noencuentro, al olvido del otro generando conflicto, guerra, dolor. La alteridad se oculta bajo el ropaje de elegantes y argumentados discursos destacados por su rigor y equilibrio conceptual. En ocasiones se mimetiza en las diversas formas de incomunicación de la comunicación, o en la comprensión del mundo como algo que está fuera y que no hace parte de lo que somos, una circunstancia separada de todo lo demás.

-Parálisis de la dimensión teologal, en la que al enrarecerse el ámbito del creer y en el contexto del denominado retorno de la religión, el logos descarrilado ha tomado la palabra en una doble dirección: el fundamentalismo de la razón o logos descuartizado en infinidad de razones (lógica, dialéctica, práctica, analítica, instrumental), y los fundamentalismos religiosos que producen la incapacidad de comprender en su entraña la propia fe, impiden enriquecerse con otras perspectivas religiosas y reconocerse en otras teologías. Se trata de la opción restringida por la propia seguridad, parálisis teologal que niega o ignora "la antorcha de la experiencia interior" (Michel Henry, 2007: 53), el necesario pathos como camino al estremecedor descubrimiento de ser en el Ser.

-La interioridad atrapada. Cuando el deseo que conduce a "Dios en el fondo del ser" (Tillich, 1972: 116) se ve amenazado por el inmediatismo, la ausencia de proyectos, la cultura de masas, las grandes urbes con sujetos anónimos, la soledad en medio de la multitud, relaciones humanas instrumentalizadas, la pérdida de credibilidad en las instituciones, la reclusión del yo y la búsqueda de nuevos asideros en algunos casos al margen de la vida social e institucional, surgen los pluralismos que fragmentan el modo de pensar y de vivir, incluida la fe, hasta afectar la intimidad del yo. Esto ha provocado el movimiento de la fe hacia el individualismo que omite el referente institucional religioso, conduce a la reclusión del yo y a la búsqueda de nuevos asideros al margen de la vida social. Es un giro hacia el individuo, (Mardones, 2005: 35) que fortalecido por la cultura y la sociedad, ha optado por la libertad de interpretación en materia religiosa. En este escenario, la interioridad se ve atrapada, y aún más, desgarrada ante la pérdida de la referencia a los demás. El excluido se siente convencido de que su existencia no tiene salida, no 
tiene futuro, ni camino. La interioridad desgarrada y sin salida no le permite sino sumergirse en una derrota y culpa contra sí mismo.

\section{5. ¿Cómo volver a las raíces místicas de 'lo humano’?}

El camino de la experiencia de fe desde la puesta en funcionamiento de la inteligencia espiritual del místico pasa por una manera de conocer de la que todos somos capaces, forma de conocer que permite ver, recorrer y padecer la dimensión de profundidad de la existencia, que hace desaparecer el ropaje que oculta la vergüenza o el miedo, porque sólo desde la conciencia de la vulnerabilidad la vida espiritual se hace fuente de esperanza, pues "no hay ninguna esperanza sin miedo" (Moltmann, 2004: 133) y emerge a la luz la alteridad como ineludible tarea e irrenunciable presencia que colorea la realidad del Tú, realidad que en la comunicación de las existencias, en la profundidad del recinto comunicable y sagrado de cada ser humano se hace un nosotros.

Para el místico, los guiños de Dios se ven a través de las cosas que se muestran colmadas de divinidad. 'Lo otro' emerge entrañable y melodioso como anuncio de eternidad, lugar de revelación.

Quisiera escribir un libro entero acerca de una piedrecilla y un par de violetas. Podría vivir sin nada más que una piedrecilla, y tener la sensación de vivir en la naturaleza poderosa de Dios. [...] y mi asombro ante el repentino descubrimiento de tanta eternidad en una piedrecilla, se ha negado a morir hasta el día de hoy (Hillesum, 2013: 653).

En un mundo de tantos contrastes, de tantas diferencias, se pone en evidencia que aunque la finalidad del creer no consiste en quedarse con la melodía sabrosa de la poesía o el silencio del resonar interior; tampoco el afianzarse a las ideas religiosas, a los dogmas, permite traspasar el umbral que descubre la vulnerabilidad desnuda y suscita la compasión.

El lenguaje puede esforzarse por dar lo mejor y lo más de sí, sin embargo la experiencia de lucidez en que consiste la mística, se narra y se expresa con lujo de detalles en aquella zona del paisaje interior donde habitan los no-conceptos. De ahí, la dificultad de mostrar con el lenguaje lo que la experiencia mística provoca en la persona. No obstante, se va evidenciando que se trata de una experiencia que afirma lo humano hasta su máxima realización como humanidad. La experiencia mística se constituye también hoy en la posibilidad para que la vida se desborde como consecuencia de este descubrir existencial sin precedentes para la experiencia personal. 
Esta fuerza que provee la experiencia interior es la única capaz de re-comprender las razones extraviadas o, testarudamente absolutizadas. Veinte, treinta o cincuenta años de pertinaz búsqueda y logros de erudición y argumentación avasallante, se desvanecen ante la manifiesta experiencia de la Presencia en lo profundo, más contundente y firme de la existencia.

En el ámbito del cristianismo, Jesucristo se hace esa luz portadora de esperanza y novedad. El creyente la ha de vivir y asumir hasta afirmar con Pablo: "no soy yo, es Cristo quien vive en mí" (Gal 2,20).

Desde el testimonio del místico contemporáneo, hemos podido comprender que interior y exterior constituyen dos experiencias de una misma realidad. Su camino interior en diálogo permanente con el exterior hace posible el descubrimiento de saberse mediador entre exterior e interior, para de este modo vivir la interioridad como el dinamismo permanente entre aquello que pasa y que es visto en la distancia; aquello que nos pasa, que provoca el centrarse sobre sí, nos toca para descentrarnos en el otro; y aquello que nos traspasa, que provoca el sobrecentramiento porque nos desborda. Es un movimiento que hace posible tomar las riendas de la propia existencia para ver y verse parte del dinamismo de eternidad que provoca el conmoverse, el diálogo y la comunión con el otro.

La prueba de conocerse, conocer el propio conocer que conduce más allá de los conceptos, pone en juego la libertad, muestra la incapacidad de la razón para iluminar todo lo que implica lo humano, da espacio al emerger de la Alteridad Radical inaprensible, inefable, y se dirige al meollo de lo humano: Dios mismo.

Ese trozo de eternidad que llevamos dentro puede ser expresado en una palabra como en diez volúmenes. Soy una persona feliz y amo esta vida, la aprecio de verdad, en el año del Señor 1942, un año más de guerra (Hillesum, 2013: 638).

Dios toma su lugar en el corazón humano: "y vendremos a él y haremos morada en él" (Jn 14,23). El místico es testigo y expresión de esta intimidad Divinidad y humanidad, motivo de desconcierto y sospecha a lo largo de la historia. Como lo diría el maestro Eckhart:

El Padre engendra su Hijo en el alma de la misma manera en que lo engendra en la eternidad, y de ninguna otra manera. (...) Y digo más: me engendra como su hijo, su mismo hijo. Y es más: no sólo me engendra como su hijo, sino como a sí mismo y se engendra así como yo mismo” (Eckhart, 2008: 54). 
En esta perspectiva se comprende también lo que escribe Etty Hillesum:

En el fondo mi vida es un escuchar ininterrumpido dentro de mí, los otros, Dios. Y cuando digo que escucho dentro, en realidad es Dios quien escucha dentro de mí. La parte más profunda y esencial del otro. Dios a Dios (Hillesum, 2013: 757).

Más allá de una confesión religiosa el testimonio de Etty abre una gran puerta de salida a la vida espiritual en el siglo XXI. Su experiencia mística es afirmación de que para Dios en su estar amando sólo basta un corazón abierto y dispuesto. Más allá de una confesión religiosa, es la orientación de la mirada lo que a su amor interesa. La inserción de Dios en el corazón de cada ser humano, habita en nosotros, es voz, sangre, respiración, se deja palpar. Basta estar atentos.

A nuestra fe cristiana le vendrá muy bien recuperar su original riqueza, el toque místico que la hace emerger. En la experiencia mística el mundo se reconcilia con la fe, con la espiritualidad recuperada en su sentido original, como camino en Dios y por Dios en medio de la vida ordinaria. En ello, el cristianismo tiene un gran regalo, Jesucristo, la encarnación, nombre de Dios y de hombre, "Dios ha puesto su tienda entre nosotros" (Jn 1,14). Así lo afirma el Vaticano II en la Constitución Gaudium et spes, no 22:

En realidad, el misterio del hombre sólo se esclarece en el misterio del Verbo encarnado. Porque Adán, el primer hombre, era figura del que había de venir, es decir, Cristo nuestro Señor, Cristo, el nuevo Adán, en la misma revelación del misterio del Padre y de su amor, manifiesta plenamente el hombre al propio hombre y le descubre la sublimidad de su vocación. Nada extraño, pues, que todas las verdades hasta aquí expuestas encuentren en Cristo su fuente y su corona.

El nuevo asomarse de la experiencia mística es hoy indicio ineludible de la necesidad de re-habilitación de la religión, para recuperarse de su puesta entre paréntesis, de su sabor a norma. También la experiencia mística es indicio de la necesidad de reconciliación de la teología con sus fuentes originales, su lenguaje provocado por la contundencia de la Experiencia. Así, en el testimonio de una mujer contemporánea se nos plantea la posibilidad de acceder a los modos como la experiencia mística y lo humano se entrelazan en entrañable abrazo.

Cada época debe tener su propia elaboración teológica, su propia reflexión sobre la espiritualidad y la mística. Y así, más allá de toda reflexión teórica, confesión religiosa, cultura o aquello que pueda verse como 
diferencia, el encuentro con la Alteridad ha de permitirnos experienciar y contemplar que toda la humanidad comparte un principio fundamental invisible pero real. Por ello, no basta con citar a Teresa de Jesús o Rahner, San Agustín o Ignacio de Loyola.

La fuerza de Julius Spier en la vida de Etty, como el acompañante y guía, el partero de su alma, es expresión de ese tú del que todos requerimos en la vida, nuestros otros como vía para afirmar nuestra propia vida movida a plenitud. La vida del ser humano es relación desde muchas perspectivas y niveles: somos lo que leemos -los libros como compañía-, somos lo que soñamos, somos lo que hablamos, somos lo que oramos, somos lo que amamos y añoramos. De ahí la importancia trascendental del cultivo de nuestras relaciones, comenzando por la exploración y reconciliación con nosotros mismos: ¿Qué tan cerca estoy de mí?

El creyente del siglo XXI está necesitado de pasar del monólogo al diálogo, reencontrándose en su interioridad. También en el logos hay una interioridad que ha estado ignorada, borrada, negada e incluso condenada.

Así, la relación entre la mística y lo humano pasa por el decantamiento de la razón teológica, por el reencuentro con el interior, lugar del Otro, de lo íntimo, que abre a lo diverso y Divino, que es en cada uno. Por ello, la razón requiere de un ensanchamiento que vaya más allá de querer superar o crear modelos y patrones con carácter universal. A este ensanchamiento se llega por la vía del reencuentro con lo humano, al interior de cada uno, escenario de la coincidencia con el Tú. "El pedacito de eternidad que llevamos dentro se puede expresar en una sola palabra o liquidarse en diez extensos volúmenes" (Hillesum, 2013: 628).

La experiencia espiritual de Etty Hillesum nos da a entender el carácter universal de la mística, es decir, el carácter universal de la Divinidad que se dona, y a su vez, el carácter profundamente humano de toda mística en el sentido y comprensión aquí propuesta, puesto que a Dios se le encuentra en medio de la humanidad, de lo humano. De modo que lo humano es detonante de la experiencia de Dios y la experiencia de Dios hace posible que emerja lo humano invitándolo a perfeccionarse, a desarrollarse, a humanizarse. Pues, aunque lo que aquí hemos investigado nos permita afirmar que la mística es lo más humano de lo humano, ella no depende sólo del esfuerzo humano. La invitación que la vida nos hace a través de los diversos modos como la realidad en cada circunstancia nos habla, es una invitación a la unión con Dios a través de la humanidad.

Podemos comenzar por convertirnos en oyentes activos de los místicos, eso sí, liberándonos un poco del incienso y de los libros (Herráiz, 2014). 


\section{Conclusión: Nuevos caminos y viejas preguntas}

Ante la pregunta y sospecha acerca de la pertinencia de la mística, se ha logrado recuperar desde el análisis de la experiencia y relato de Etty Hillesum que la invitación fundamental dirigida al ser humano, sobrepasa límites y fronteras geográficas, sociales, religiosas e intelectuales, y que nuestra tarea teológica demanda cada vez más apertura y tolerancia al estar ante una responsabilidad histórica orientada al reencuentro con lo genuinamente humano, a la reconciliación y al diálogo movido por la fuerza del silencio elocuente, movido por la Oscura Diafanidad que nos habita.

Ante la desconfianza y la duda en relación con un futuro más humano, se recupera la apuesta por un modo de vivir lo humano que se hace posible al incorporar el extracto que emana de lo mejor del interior, del deseo profundo de una vida plena, impulsada por el requerimiento de pensar la acción, tarea fundamental de la existencia, anhelo de encontrar el sentido del sin sentido en medio de las circunstancias actuales.

La experiencia mística y lo humano se requieren mutuamente, pues lo humano anhela expresar y colmar su nostalgia de la Presencia, y la experiencia mística se dice y se pronuncia en lo humano.

Ante el progresivo fracaso de la autonomía de lo humano, hemos descubierto que no sabemos ser nosotros mismos. Ser nosotros, ser yo, ser tú, es confesar experiencialmente que no somos, que no soy, que no eres porque somos en... un Tú que nos desborda e inhabita a la vez que nos mueve y nos lanza irremediablemente a los otros, lugar de realización plena de la experiencia del Tú, ser en el Ser, alteridad radical.

El asunto propuesto en esta reflexión ha quedado apenas planteado, y emergen ahora nuevas preguntas y nuevos caminos posibles.

En la historia de la mística se han vivido varios momentos, desde su descubrimiento, la fuerza que adquirió en la edad media y que se afirmó en la mística clásica española, lo que se ocultó o quedó velado en la modernidad en el intento de hegemonía de la razón occidental, y en nuestros tiempos el nuevo emerger de una experiencia que estaba dormida y que desde los nuevos testigos y místicos no deja de decirse. De modo que la Mística aún demanda de la teología espiritual mucha atención.

Al tratarse de un itinerario espiritual que no se restringe a una confesión religiosa específica, y que además está muy cercano a la experiencia del creyente del siglo XXI, se abren otros caminos de aproximación y estudio sobre la experiencia mística, su lugar y su sentido en el diálogo interreligioso, incluso se plantean nuevos puntos de convergencia para el diálogo con oriente y su riqueza espiritual milenaria. 
Al final de esta reflexión la autora reconoce una vez más la gran desproporción entre el lenguaje que ha pretendido aproximarse de otro modo al fundamento de lo humano, y ese irrenunciable referente y pretexto que se nos muestra en la discreta elocuencia de la experiencia mística contemporánea.

\section{REFERENCIAS}

-Cubides, H. (1999). La dialéctica comprender/explicar: Una reflexión filosófica desde la hermenéutica. Revista Nómadas (11), 267-273.

-De Almeida, F. (2014). Del vivir apático al vivir simpático: Sufrimiento y muerte. Sao Paulo: San Pablo.

-De Chardin, T. (2009). El fenómeno humano. En J. Melloni, Voces de la Mistica. Invitación a la contemplación (pp. 115-119). Madrid: Herder.

-Galván, J. M. (2006). De Lubac: el misterio del hombre en el Misterio de Dios. Anuario Filosófico, 39 (1), 163-177.

-Marion, J. L. (2006). El tercero o el relevo del dual. Buenos Aires: San Benito.

-Dobner, C. (2007). Etty Hillesum pagine mistiche. Milano: Áncora.

-Dussel, E. (1969). El Humanismo Senita. Argentina: Eudeba.

-Eckhart, M. (2008). El fruto de la nada. Madrid: Siruela.

-Geffré, C. (1983). El cristianismo ante el riesgo de la interpretación. Madrid: Cristiandad.

-Gelabert, M. (1983). Experiencia bumana y comunicación de la fe. Madrid: Paulinas.

-González de Cardedal, O. (1997). Aprender a Conocer, Aprender a Ignorar. En J. L. Corzo (Ed.), Escuchar el mundo, oír a Dios (pp. 15-33). Madrid: PPC.

-González Faus, J. (2008a). Etty Hillesum, una vida que interpela. Madrid: Sal Terrae.

-González Faus, J. (2008b). Carta a Gutiérrez. En C. de Prado \& P. Hughes, (Eds.), Libertady Esperanza (pp. 55-65). Lima: CEPO.

-Gutiérrez Cuartango, C. (2008). Experiencia mística y humanización: repercusiones en la vida. Nova et Vetera: Temas de Vida Cristiana, 32 (65), 147-175.

-Henry, M. (2007). Filosofía y Fenomenología del Cuerpo. Salamanca: Sígueme.

-Herráiz, M. (2014). Entrevista personal/Entrevistadora: Rosana Navarro, CITeS, Ávila.

-Hillesum, E. (2013). Diario. Edizione Integrale. Milano: Adelphi.

-Kierkegaard, S. (2009).Una reflexión sobre la existencia bumana. México: Universidad Iberoamericana.

-Kaufmann, C. (2004). Interioridad y mística cristiana. En J. Martin Velasco et. al., La interioridad: un paradigma emergente (pp. 53-67). Madrid: PPC.

-Lebeau, P. (1999). Etty Hillesum, Un Itinerario Espiritual. Madrid: Sal Terrae.

-Lévinas, E. (1987). De otro modo que ser o más allá de la esencia. Salamanca: Sígueme.

-Lévinas, E. (1977). Totalidad e infinito: Ensayo sobre la exterioridad. Salamanca: Sígueme. 
-Mardones, J. M. (2003). Religión y Humanismo. La religión en la emergencia de una cultura global. En M. L. Amigo Fernández (Ed.), Humanismo para el Siglo XXI (pp. 445-452). Bilbao: Universidad de Deusto.

-Mardones, J. M. (2005). La transformación de la religión. Madrid: PPC.

-Martin Velasco, J. (2004). La interioridad: un paradigma emergente. Madrid: PPC.

-Martin Velasco, J. (2007a). La experiencia cristiana de Dios. Madrid: Trota.

-Martin Velasco, J. (2007b). Mistica y Humanismo. Madrid: PPC.

-Martin Velasco, J. (2011). Palabras y lugares de la experiencia mística hoy. En J. García \& F. Prado (Eds.), Mujeres y hombres de Dios, Mistica y Testimonio (pp. 19-60). Madrid: Publicaciones Claretianas.

-Moeller, C. (1960). Humanismo y Santidad. Testimonios de la Literatura Occidental. Barcelona: Juventud.

-Mommaus, P. (2003). The Riddle of Christian Mystical Experience: The Role of the Humanity of Jesus. Leuven, Belgium: Peters Pub.

-Moltmann, J. (2004). La venida de Dios. Escatología Cristiana. Salamanca: Sígueme.

-Quesada Talavera, B. (2011). Aproximación al concepto de Alteridad en Levinás. Investigaciones fenomenológicas: Anuario de la Sociedad Española de Fenomenología (3), 393-405.

-Panikkar, R. (1999). La intuición cosmoteándrica. Madrid: Trotta.

-Panikkar, R. (2000). Elogio de la Sencillez. Pamplona: Verbo Divino.

-Panikkar, R. (2005). De la mística, experiencia plena de la Vida. Barcelona: Herder.

-Rahner, K. (1980). Elemente der Spiritualität in der Kirche der Zukunft. En K. Rahner, Schriften zur Theologie (Band XIV, pp. 368-381). Zürich, Einseideln \& Köln: Benzinger Verlag.

-Rahner, K. (2002). Escritos de Teología (Vol. IV). Madrid: Cristiandad.

-San Agustín (2006). Las Confesiones. México: Lectorum.

-Schillebeckx, E. (1994). Los hombres relato de Dios. Salamanca: Sígueme.

-Schillebeeckx (1973). Interpretación de la fe. Aportaciones a una teología hermenéutica y crítica. Salamanca: Sígueme.

-Tillich, P. (1972). Teología sistemática. La razón y la revelación. El ser y Dios. Barcelona: Ariel.

-Torralba, F. (2009). Acto de clausura del II Congreso Internacional sobre mística y pensamiento contemporáneo. Ávila: CITES.

-Von Balthasar, U. (1985). La oración contemplativa. Madrid: Encuentro.

-Zubiri, X. (1975). El problema teologal del hombre. Madrid: Cristiandad.

Sumario: Introducción: Lo humano y la experiencia mística como propuesta de una reflexión teológica; 1 . El testimonio del sujeto como recurso irrenunciable; 2. Aproximación a lo humano y la experiencia mística; 2.1. Lo humano como lugar de la experiencia espiritual; 2.1.1. Alteridad como modo de ser humano; 2.1.2. La actitud teologal que dinamiza lo humano; 2.1.3. Interioridad como profundidad y búsqueda; 2.2. La experiencia mística, un modo de vivir lo humano; 3. Desvelamiento de lo humano desde la experiencia mística de Etty Hillesum; 4. La esperanza de 'lo humano' como intuición y demanda de la ex- 
periencia mística; 5. ¿Cómo volver a las raíces místicas de 'lo humano’?; Conclusión: Nuevos caminos y viejas preguntas; Referencias. 